Preprint. Final version appears as:

Morgan, R., Robertson, J., Lennard, C., Hubbard, K. \& Bull, P. (2010) Quartz grain surface textures of soils and sediments from Canberra, Australia: A forensic reconstruction tool. Australian Journal of Forensic Sciences. DOI 10.1080/00450610903258110

\title{
Quartz grain surface textures of soils and sediments from Canberra, Australia: A forensic reconstruction tool.
}

Ruth M Morgan $^{\mathrm{a}}$, James Robertson ${ }^{\mathrm{b}}$, Chris Lennard ${ }^{\mathrm{c}}$, Kimberley Hubbard ${ }^{\mathrm{c}}$ and Peter A Bull ${ }^{\mathrm{d}}$

${ }^{a}$ UCL Jill Dando Institute of Crime Science, 35 Tavistock Square, London WC1H 9EZ, UK

${ }^{\mathrm{b}}$ Forensic and Data Centres, Australian Federal Police, GPO Box 401, Canberra, ACT 2601, Australia

${ }^{\mathrm{c}}$ National Centre for Forensic Studies, University of Canberra, ACT 2601, Australia

${ }^{\mathrm{d}}$ University of Oxford Centre for the Environment, South Parks Road, Oxford, OX1

3QY, UK

Communicating author: Ruth Morgan

Ruth.morgan@ucl.ac.uk

Tel: +442031083037

Fax: +442031083088 
Quartz grain surface textures of soils and sediments from Canberra, Australia: A forensic reconstruction tool.

Ruth M Morgan ${ }^{\mathrm{a}}$, James Robertson ${ }^{\mathrm{b}}$, Chris Lennard ${ }^{\mathrm{c}}$, Kimberley Hubbard ${ }^{\mathrm{c}}$ and Peter A Bull ${ }^{\mathrm{d}}$

\begin{abstract}
This paper provides our first forensic quartz grain surface texture analysis of soils from the southern hemisphere. Sediment and soil samples were collected from a simulated crime reconstruction in the environs of Canberra, Australia, which comprised a murder site, an alibi site and a body deposition site. Following the successful application of quartz grain surface texture analysis from many case locations in England ${ }^{1}$ and more recently in Switzerland ${ }^{2}$, this paper examines the potential for the application of this technique from areas around Canberra. The very specific geological history of the Australian continent provides new challenges for forensic reconstruction techniques. The quartz grain surface textural analysis undertaken indicates that clear differences between the three locations can be identified, enabling the successful differentiation of samples taken from the three distinct sites. This provides a means of undertaking exclusionary analysis and disproving an alibi location as being a possible source for material derived from the murder site or the body deposition site. These findings indicate that this form of geoforensic analysis has great potential for crime scene investigation of mixed-source physical trace geoforensic evidence in Australia. It also has the potential to provide an independent line of enquiry to other well established geoforensic techniques.
\end{abstract}

Key words: quartz grain surface textures, scanning electron microscopy (SEM), forensic geoscience, Canberra, soil. 


\section{Introduction}

\subsection{Forensic geoscience}

Forensic geoscience is a rapidly growing and developing discipline $\mathrm{e}^{3-5}$. It pertains to the use of soil, sediments, rocks and geology in matters of the law and has been demonstrated to have a wide range of applications at a range of scales spanning from the micro to the macro. The number of related analytical techniques (chemical, physical and biological) being applied in a forensic context is growing ${ }^{6-11}$ and this is steadily increasing the capabilities of geoforensic investigations.

A distinctly geoforensic philosophical framework has been articulated within which forensic geoscience should operate, providing a contrast to the approaches adopted by the more traditional geosciences ${ }^{3,12}$. Such a framework is very important as it will have an impact upon the way geoforensic evidence is collected, analysed, interpreted and presented. Specifically, soil evidence is a probabilistic form of evidence as opposed to the more 'categorical' and 'probabilistic and quantitative' forms of evidence such as fingerprints and $\mathrm{DNA}^{13}$. Therefore, the primary aim in forensic geoscience must always be to exclude samples from having a similar provenance as opposed to looking to establish an association or 'match' between samples. There are three subsidiary principles for forensic geosciences; firstly, account must be taken of the different nature of analytical techniques and their different capabilities in differing contexts. Secondly, there is a need for independent lines of enquiry for corroboration and increasing the evidential weight of a particular form of evidence. Thirdly, there is a requirement for an appreciation of the advantages and disadvantages of exotic (rare) and more ubiquitous components of a soil/sediment in different contexts ${ }^{3,12}$. As every investigation is different, with different impinging external factors, it is important that the individual context is recognized so that geoforensic evidence can be utilized in a meaningful and appropriate way to generate useful intelligence and evidence.

Adhering to this specifically geoforensic framework and using its principles in a sensitive way appropriate for the individual context is highly important for generating credible geoforensic intelligence and evidence. However, it is also important not to overlook the important role of experimental studies. Experimental work, in general, can build up a body of knowledge to establish primary theories concerning the behaviour of geoforensic materials. More specifically, there will be occasions when it 
is important to undertake specific experiments that directly pertain to the investigation currently being undertaken ${ }^{14}$. This provides a specific context within which it is possible to more accurately collect, analyse and interpret geoforensic evidence ${ }^{15,16}$.

\subsection{Quartz grain surface texture analysis}

The analysis of quartz grain morphology and surface textures as an indicator of grain history is a well established technique for environmental reconstruction ${ }^{17}$. The different textures that can be identified provide an indication of the history of a particular grain and can indicate not only the original provenance of a grain but also its journey over time. It is only relatively recently that the technique has been presented in the literature in a format suitable for geoforensic applications, with a derived classification system that enables quartz grains to be typed and compared to one another ${ }^{1}$.However, it is becoming accepted as a useful tool in the UK, with a number of cases where the technique has been utilized successfully in combination with other independent geoforensic techniques ${ }^{18}$. The embryonic database that has been constructed of the different quartz grain types found in different locations in England ${ }^{1}$ has demonstrated that there is potential for this type of analysis to provide very useful information, not only in comparative investigations (where a soil sample from a suspect, their clothing or vehicle is compared to a soil sample taken from a site of interest such as a murder site or a body deposition scene) but also in 'seek-andfind' investigations (where the location of a site of interest is not known but material has been recovered that is thought to have originated from that site).

This technique appears to have significant capabilities in the UK, which are still being intensively investigated; however, so far these capabilities have not yet been fully tested in a forensic context further afield. Initial work in Switzerland appears to demonstrate that quartz grain analysis may be able to differentiate effectively between soil samples derived from different locations in a region which itself has a very more complex geological history to that found in the $\mathrm{UK}^{2}$. Such findings indicate that this technique may be a useful tool for forensic investigations in other regions. In the light of this, this study aimed to establish whether quartz grain surface texture analysis has potential for geoforensic applications in Australia.

\section{Murder case scenario in Canberra}


In order to assess whether quartz grain surface texture analysis could be a viable form of analysis in Australia, an experimental study was set up in Canberra and its environs. A hypothetical murder case was devised where a suspect killed the victim in one location (the murder site), buried the body in another (the body deposition site), and provided a third site as their 'alibi site'. Such a scenario was deemed to mimic the forensic reality encountered in real-life murder investigations since it was set up with no knowledge of relevant geology or geomorphological features in the area. Indeed, the locations were chosen in environs that were sufficiently typical of sites where a body may well be deposited, buried or hidden from view.

\subsection{The setting}

The three sites (designated as the murder scene, deposition site and alibi site) were located around Canberra as shown in Figure 1. These sites were subsequently found to be situated in three distinct soil-landscape associations; regions of Umburra, Wanniassa and Florey, respectively (as defined by Walker ${ }^{19}$ and Sleeman and Walker ${ }^{20}$ ). The Umburra soil-landscape association is characterised by lithosols and shallow stoney soils, with igneous and sedimentary outcrops. In contrast, the Wanniassa association is predominantly composed of red earth and red and yellow podzolic soils, whilst the Florey regions are very similar to Wanniassa but have a greater degree of moderately to poorly drained soils ${ }^{20}$.

The murder scene was situated in a wooded area in Aranda (Figure 1). This location was chosen because it is one of the few remaining suburbs in Canberra that comprises bushland (Table 1). The particular site sampled was approximately $50 \mathrm{~m}$ from the nearest houses and therefore provided a concealed location for a crime to take place. The deposition site, in contrast, was more sparsely vegetated (Table 1), with fewer trees and more exposed soil. This location was deemed to provide good conditions for digging a grave to dispose of the body that had been transported from the more populated murder scene. The alibi site also provided a contrast in that it was located in a more populated suburb where building work was being undertaken (Table 1). This was considered to be a very plausible location from which a suspect could claim to have picked up soil on their vehicle, clothing or footwear.

\subsection{Sampling procedure and analysis}


Three samples of approximately $10 \mathrm{~g}$ of surficial soil were taken from each site (in addition to a fourth taken from the body deposition site) to ensure that account could be taken for intra sample variability in the subsequent analyses. Each sample was then wet sieved in distilled water to remove the silt and clay fraction and dried overnight in a drying oven at $40^{\circ} \mathrm{C}$. Fifty sand-sized quartz grains were then taken from each sample (selected by the nearest grain principle) and mounted onto a scanning electron microscope (SEM) stub. Each stub was then gold coated and observed under the SEM, where each grain was typed and recorded in the manner set out by Bull and Morgan ${ }^{1}$. The classification of each type was reached by first assessing the shape of each grain (whether rounded, sub-rounded, sub-angular, angular) and then proceeding through the different levels of classification to take into account the different surface features and textures present and the state of the edges on each grain (for full details please see the full classification system outlined in Bull and Morgan $^{1}$ and the description of the quartz grain types described in section 2.3).

\subsection{Results}

Three distinguishable quartz grain types were identified in the soil samples from the three locations as shown in Table 1. The distinguishing characteristics of each grain type were both morphological and surficial. For example, Type I grains (found in the samples taken from the alibi site) were generally sub-angular in shape, strained quartz grains with high relief (Table 1). There was also indication of a metamorphic origin of these grains, with many of the grains exhibiting elongated, heart or bent shapes (photographs A and B in Table 2). Some of these Type I grains exhibited euhedral features (photograph $\mathrm{C}$ in Table 2), and most had large conchoidal fractures and breakage blocks. There were generally only discrete areas of edge abrasion (suggesting that the grains had not travelled far from their original provenance) and selected areas of the grains exhibited chemical precipitation features.

Type II grains (identified in the samples taken from the murder scene) were much more rounded, being found to be generally round to sub-round (Table 1). They generally exhibited extensive chemical precipitation, which masked a lot of the surface features apart from old conchoidal fractures and breakage blocks (photograph A in Table 2). The particularly distinctive feature of these Type II grains were the presence of filaments (photographs B and C Table 2) adhering to the grain surfaces. 
Such features have been found on quartz grains collected in the UK from organic/humus rich sites and are generally indicative of a woodland provenance. It is of note that the Type II grains were found exclusively in the samples taken from the woodland murder scene and that some of these grains were elongated.

Type III grains (identified in samples taken from the body deposition site) provided an additional contrast. These grains were angular in shape with no edge abrasion (Table 1) and many of the surfaces were dulled by smoothing that was caused by solution processes (photographs $\mathrm{A}$ and $\mathrm{B}$ in Table 2). In addition, a number of the grains were fragments or shards of quartz (photograph C, Table 2). The grains are likely to have been released from their parent rock by normal weathering processes, where it underwent mechanical rounding (during one or more cycles of erosion). Subsequently, these grains were incorporated into a sedimentary body and then lithified into a rock. Erosion of that rock, normally under prolonged weathering processes, would have led to fragmentation of the more rounded grains along original strain directions, which would then lead to the production of shards and fragments of quartz. After their release, subsequent processes may leave features on the surfaces of these shards and fragments that are indicative of present chemical solution processes from the present cycle of erosion.

Table 3 presents the numbers of each quartz grain type present in each sample analysed, and also indicates the number of elongated grains that were identified at each site. It is very interesting that, at each site, there was only one quartz grain type found in the samples. This strikes a contrast with the finding in the UK where, on average, there will be two or three different quartz grain types present in soil samples taken at any specific location ${ }^{1}$. Indeed, not only is there only one type of quartz grain at each location, but there are elongated grains present in each sample, a feature normally indicative of a metamorphic provenance. Again, such a feature is comparatively rare in the UK, perhaps reflecting the different geological histories of this region of Canberra. Another interesting difference between these samples and those previously analysed from the UK, is the presence of quartz fragments resulting from erosion and weathering processes acting on strained quartz at the body deposition site. Further work is required to assess whether the single grain types identified in this study are highly specific to these particular areas or whether in other 
regions mixtures of grain types are more prevalent (an issue that is currently being investigated by the analysis of further samples from different regions of Australia). However, the UK database ${ }^{1}$ has demonstrated that of all the samples analysed from forensic cases to date (738 samples totaling over 25,000 individual quartz grains), there is no occasion where the assemblage of grain type(s) present in a sample from one location is the same as samples from any other location included in the database. Of course, for every specific forensic case, an assessment of inter- and intra-sample variability is important in order to ensure meaningful and accurate interpretations of the results.

In contrast, it is worth noting the presence of filaments on the Type II grains collected from the woodland murder scene. These features are distinctive and their presence in the murder scene samples is consistent with their occurrence on quartz recovered from soil samples derived from woodland locations in the UK.

\section{Implications}

These preliminary findings have implications for the use of quartz grain surface texture analysis for forensic applications in Australia.

1. Each site has only one type of quartz grain present, which suggests that the source rocks are composed of only one type of quartz. It is therefore highly likely that spatially distinct areas exist within the Canberra region and, therefore, there is potential for exclusionary conclusions to be reached when comparing soil samples derived from different sources (i.e. murder site, alibi site, vehicle or clothing belonging to the suspect). Such intelligence may prove to be highly useful to criminal investigations.

2. The evidence of metamorphic processes in these samples indicates that different geological histories for different regions will be reflected in the quartz grain surface textures and that this adds to the ability to differentiate between samples from different locations based on this property. It is therefore possible that the analysis of quartz grain surface textures may be useful in Australia for so called 'seek and find' investigations, where a source 
for soil/sediment material is sought, as well as the more common 'compare and exclude' investigations.

3. Quartz grain surface texture analysis appears, from this preliminary study, to provide a high discriminatory power between soil samples of different provenance. There is therefore potential for this technique to provide a powerful independent line of enquiry to complement other geoforensic forms of analyses such as chemical, physical and palynological ${ }^{21-28}$ investigations in Australia. Independent techniques which provide corroborative results ${ }^{18}$ have the ability to add significant evidential weight to geoforensic evidence presented in court.

Whilst this study provides only a small scale and preliminary investigation into the potential of quartz grain analysis in Australia, these initial findings are positive and indicate that further work in this area is warranted. We demonstrate here, for the first time, that quartz grain surface texture analysis is a useful line of enquiry for geoforensic investigations in Australia. Of course, it will always be crucial to establish the specific context of a particular forensic investigation in order to carry out appropriate forensic analyses that takes all the pertinent impinging factors into account; however, the potential for this technique in Australia, if added to the armoury of the forensic geoscientist, appears to be very promising.

\section{Acknowledgements}

RM acknowledges the funding provided by the EPSRC (grant EP/G026718/1). The authors would also like to thank Dr Anthony Ringrose-Voase (CSIRO) for providing the soil map of the Canberra region and Ailsa Allen (University of Oxford) for cartographic services.

\section{References}

1. Bull, P. A. and Morgan, R. M. 2006 Sediment Fingerprints: A forensic technique using quartz sand grains. Sci Justice 2006;46(2):64-81

2. Freudiger-Bonzon, J., Bull, P. A., and Morgan, R. M. A geoforensic comparison of physical and chemical analysis of soils from the plateau region of Switzerland. 2nd International Workshop on Criminal and Environmental Forensics 2007, Edinburgh, UK 30 October - 1 November 2007 p43 
3. Morgan, R. M. and Bull, P. A. The philosophy, nature and practice of forensic sediment analysis. Prog Phys Geog 2007;31(1):43-58

4. Ruffell, A. and McKinley, J. Geoforensics. Wiley Blackwell; 2008. 340pp

5. Ritz, K., Dawson, L. and Miller, D. Criminal and Environmental Soil Forensics. Springer;2008. 400pp

6. Riding, J. B., Rawlins, B. G. and Coley, K. H. Changes in soil pollen assemblages on footwear worn at different sites. Palynology 2007;31:135-151

7. MacDonald, L.M., Singh, B.K., Thomas, N., Brewer, M.J., Campbell, C.D., Dawson, L.A. Microbial DNA profiling by multiplex terminal restriction fragment length polymorphism for forensic comparison of soil and the influence of sample condition. J Appl Microbiol 2008 ;105 (3):813-821

8. Meyers, M. S., and Foran, D. R. Spatial and temporal influences on bacterial profiling of forensic soil samples. J Forensic Sci 2008;53(3): 652-660

9. Heath, L.E. and Saunders, V. A. Spatial variation in bacterial DNA profiles for forensic soil comparisons Can. Soc. Forensic Sci. J. 2008 ;41(1): 29-37

10. Pringle, J.K., Jervis, J., Cassella, J.P., Cassidy, N.J. Time-lapse geophysical investigations over a simulated urban clandestine grave J Forensic Sci 2008;53 (6):1405-1416

11. Schultz, J. J. Sequential monitoring of burials containing small pig cadavers using ground penetrating radar. J Forensic Sci 2008;53(2): 279-287

12. Morgan, R. M. and Bull, P. A. Forensic Geoscience and Crime detection. Identification, interpretation and presentation in forensic geoscience. Minerva Med 2007;127 (2):73-90

13. Broeders, A. P. A. Of earprints, fingerprints, scent dogs, cot deaths and cognitive contamination - a brief look at the present state of play in the forensic arena.

Forensic Sci Int 2006;159 148-157

Morgan, R. M., Cohen, J., McGookin, I., Murly-Gotto, J., O’Connor, R., Muress, S., Freudiger-Bonzon, J. and Bull, P. A. The relevance of the evolution of experimental studies for the interpretation and evaluation of some trace physical evidence Science and Justice 2009 (in press).

14. Morgan, R. M., Allen, E., Lightowler, Z. L., Freudiger-Bonzon, J. and Bull, P. A. A forensic geoscience framework and practice. Policing: A Journal of Policy and Practice 2008;2: 185-195 
15. Morgan, R. M., Freudiger-Bonzon, J., Nichols, K. H., Jellis, T., Dunkerley, S., Zelazowski, P. and Bull, P. The geoforensic analysis of soils from footwear. In Ritz, K., Dawson, L. and Miller, D. (Eds) Criminal and Environmental Soil Forensics. Springer. 2008. 400pp

16. Bull, P. A., Whalley, W. B. and Magee, A. W. An annotated bibliography of environmental reconstruction by SEM 1962-1985. BGRG Tech. Bull.,35 1985.

17. Morgan, R. M., Wiltshire, P., Parker, A. and Bull, P.A. The Role of Forensic Geoscience in Wildlife Crime Detection. Forensic Sci Int 2006;162: 152-162.

18. Walker, P. H. Soil-landscape associations of the Canberra area. CSIRO Aust. Div. Soils Divi Rep. No 29. 1978.

19. Sleeman, J. R., and Walker, P. H. The soils of the Canberra district, Soils and Land Use Series 58. CSIRO Melbourne. 1979.

20. Horrocks, M. and Walsh, K. A. J.A Forensic palynology: assessing the value of the evidence. Rev Palaeobot Palyno 1998;103(1-2):69-74

21. Horrocks, M., Coulson, S. A. and Walsh, K. A. J. Forensic palynology: variation in the pollen content of soil on shoes and in shoeprints in soil. J Forensic Sci 1999;44 (1):119-122

22. Mildenhall Forensic Palynology in New Zealand. Rev Palaeobot Palyno 1990;64: 227-234

23. Mildenhall, D. C. Hypericum pollen determines the presence of burglars at the scene of a crime: An example of forensic palynology. Forensic Sci Int 2006;163(3):231-235

24. Mildenhall, D. C. An unusual appearance of a common pollen type indicates the scene of the crime. Forensic Sci Int 2006;163(3): 236-240

25. Mildenhall, D. C., Wiltshire, P. E. J. and Bryant, V. M. Forensic Palynology: Why do it and how it works. Forensic Sci Int 2006;163(3): 163-172

26. Milne, L., Bryant, V. M. and Mildenhall, D. Forensic Palynology. In Coyle, H. M. (Ed) Forensic Botany: Principles and Applications to Criminal Casework. CRC Press. 2005; 217-252.

27. Milne, L. A Grain of Truth: How Pollen Brought a Murderer to Justice. Reed New Holland (Australia) 2005; 175pp

\section{Table captions}

Table 1 The three different locations and representative soil and quartz grain types. Table 2 Description of the different quartz types from the three different locations 
Table 3 The number of quartz grain types from each sample.

\section{Figure captions}

Figure 1 A map depicting the three sampling sites and the associated soil/landscape association 